\title{
Binge/purge thoughts in nonsuicidal self-injurious adolescents: An ecological momentary analysis
}

\section{Citation}

Shingleton, Rebecca M., Kamryn T. Eddy, Aparna Keshaviah, Debra L. Franko, Sonja A. Swanson, Jessica S. Yu, Meera Krishna, Matthew K. Nock, and David B. Herzog. 2013. “Binge/purge Thoughts in Nonsuicidal Self-Injurious Adolescents: An Ecological Momentary Analysis." International Journal of Eating Disorders 46 (7) (June 3): 684-689. doi:10.1002/eat.22142.

\section{Published Version}

10.1002/eat.22142

\section{Permanent link}

http://nrs.harvard.edu/urn-3:HUL.InstRepos:33461070

\section{Terms of Use}

This article was downloaded from Harvard University's DASH repository, and is made available under the terms and conditions applicable to Open Access Policy Articles, as set forth at http:// nrs.harvard.edu/urn-3:HUL.InstRepos:dash.current.terms-of-use\#OAP

\section{Share Your Story}

The Harvard community has made this article openly available.

Please share how this access benefits you. Submit a story.

\section{Accessibility}




\title{
Binge/Purge Thoughts in Nonsuicidal Self-Injurious Adolescents: An Ecological Momentary Analysis
}

\author{
Rebecca M. Shingleton, MA ${ }^{1,}{ }^{*}$, Kamryn T. Eddy, $\mathrm{PhD}^{2,3}$, Aparna Keshaviah, ScM ${ }^{2}$, Debra L. \\ Franko, $\mathrm{PhD}^{4}$, Sonja A. Swanson, $\mathrm{ScM}^{5}$, Jessica S. Yu, BA ${ }^{6}$, Meera Krishna, BA ${ }^{2}$, Matthew \\ K. Nock, PhD $^{7}$, and David B. Herzog, MD ${ }^{3}$ \\ ${ }^{1}$ Department of Psychology, Boston University, Boston, Massachusetts \\ ${ }^{2}$ Department of Psychiatry, Massachusetts General Hospital, Boston, Massachusetts \\ ${ }^{3}$ Harvard Medical School, Boston, Massachusetts \\ ${ }^{4}$ Department of Counseling and Applied Educational Psychology, Northeastern University, \\ Boston, Massachusetts \\ ${ }^{5}$ Harvard School of Public Health, Boston, Massachusetts \\ ${ }^{6}$ Department of Psychology, Rutgers University, Newark, New Jersey \\ ${ }^{7}$ Department of Psychology, Harvard University, Cambridge, Massachusetts
}

\begin{abstract}
Objective-Adolescents who self-injure often engage in bingeing/purging (BP). Ecological momentary assessment (EMA) has potential to offer insight into the relationship between selfinjury and BP. The aims of this study were to examine the frequency and context of BP using EMA in a sample of nonsuicidal self-injurious (NSSI) adolescents.

Method-Thirty adolescents with a history of NSSI responded to questions regarding selfdestructive thoughts/behaviors using a palm-pilot device. Descriptive analyses compared thought/ behavior contexts during reports of BP and NSSI thoughts/behaviors (occurring together vs. individually).
\end{abstract}

Results-BP thoughts were present in 22 (73\%) participants, occurring on 32\% of the persondays recorded; 59\% of these participants actually engaged in BP behavior. Seventy-nine percent of BP thoughts co-occurred with other self-destructive thoughts. Adolescents were more often with friends/peers than alone or with family when having BP thoughts. Worry and pressure precipitated both BP and NSSI thoughts, but perceived criticism and feelings of rejection/hurt were associated more often with BP thoughts than with NSSI thoughts.

Discussion-BP thoughts and behaviors were common in this sample, often occurring with other self-destructive thoughts. Future EMA research is needed to address the function of BP symptoms, the contextual variables that increase risk for BP thoughts, and the factors that predict the transition of thoughts into behaviors in adolescents with and without self-injury.

\section{Keywords}

eating disorders; adolescents; non-suicidal self-injury; ecological momentary assessment

\footnotetext{
(c) 2013 Wiley Periodicals, Inc.

${ }^{*}$ Correspondence to: Rebecca M. Shingleton, Department of Psychology Boston, Boston University, Boston, MA, USA. rshingleton@gmail.com.
} 


\section{Introduction}

Eating disorder (ED) behaviors have been cited in more than half of individuals who selfinjure, ${ }^{1}$ and self-injury tendencies are associated with increased ED symptom-atology in young adolescents. ${ }^{2}$ Within ED samples, nonsuicidal self-injury (NSSI) is most frequently reported in individuals who binge and purge (BP) and both sets of behaviors have been associated with similar maintenance factors [e.g., affect dysregulation, impulsivity, selfcriticism ${ }^{1}$ ]. Despite this high degree of overlap, minimal research has been dedicated to understanding the context surrounding these symptoms, which provides information as to when and why individuals consider engaging in these self-destructive behaviors.

Ecological momentary assessment (EMA) is a type of data collection that occurs in real-time and has been used in the natural environment to study both bingeing/purging (BP) and NSSI. ${ }^{3-6}$ The body of EMA research illustrates that a range of proximal cues [e.g., negative affect, ${ }^{5-8}$ time $^{9}$ ] may impact BP and NSSI behaviors, and offers a strong foundation for EMA-based methods linking different contextual variables to specific symptoms. EMA research has the potential to provide clinically relevant information to inform treatment, particularly cognitive behavioral therapy, which focuses on identifying associations between thoughts, feelings, and problematic behaviors. Additionally, real-time data offer specific details that may aid clinicians' ability to conduct accurate analyses of maladaptive symptoms, and to deliver timely and targeted interventions to a patient. ${ }^{10}$ However, the vast majority of EMA research in NSSI and EDs has been conducted in participants over the age of 18 , even though symptoms for both often develop during adolescence. ${ }^{11,12}$ Further, even though these behaviors often co-occur, the majority of research examining self-injury and eating pathology has been conducted in ED samples, with no EMA research focused on the context of this co-occurrence in adolescence.

Although feasibility of using EMA in other domains has been demonstrated with adolescents, [e.g., depression ${ }^{13}$ and smoking cessation ${ }^{14}$ ], to our knowledge, only one study has used this methodology in a younger sample with ED features (age range 8-13 years), reporting that thoughts about food (as opposed to negative emotions) preceded loss of control eating. ${ }^{15}$ Two EMA reports of $\mathrm{NSSI}^{5,16}$ focused on affect-related predictors (i.e., lability, emotion regulation, and change in affect) of self-injury in the same sample of adult patients with bulimia nervosa, although neither study analyzed predictors of BP symptoms. To better understand how the immediate environmental and emotional context impacts BP symptoms in an adolescent NSSI sample, real-time data in a younger population are needed. Whether the contexts in which these types of symptoms occur are similar or different has not been studied.

The objective of the current study was to examine BP thoughts and behaviors within a sample of adolescents who were recruited for their history of NSSI. ${ }^{17}$ The first aim was to investigate the frequency and co-occurrence of BP thoughts/behaviors with self-injury and other self-destructive thoughts/behaviors in this sample of NSSI adolescents. We hypothesized that BP thoughts and behaviors would be present in the majority of the sample, given the high rates of adolescents experiencing both sets of symptoms reported in the literature. ${ }^{1}$ Our second aim was to investigate the context (i.e., with whom, current activity, affect, what led to the thought, and reason for engaging in behavior) surrounding BP thoughts/behaviors. Based on prior EMA studies, we hypothesized that negative affect and situations involving eating would be associated with BP thoughts and behaviors. 


\section{Method}

\section{Participants}

Thirty adolescents (ages 12-19) who reported engaging in NSSI within the past 2 weeks and who had access to a computer were included. ${ }^{17}$

\section{Procedure}

All participants (and their parents, for participants under 18 years of age) provided informed assent/consent to participate in the original study. The adolescents were trained to use the personal digital assistant (PDA) to collect EMA data, and were asked to respond to questions on their PDA device for 14 days. Each evening, participants were instructed to upload their data to a secure server. They were compensated $\$ 100$ for participating and, if their compliance rate was $80 \%$ or greater, the adolescents had the option to keep the PDA device ( $\$ 135$ value). Study procedures were approved by the Institutional Review Board at Harvard University. Further details can be found in Nock and colleagues ${ }^{17}$ published manuscript.

\section{Assessments}

Schedule for Affective Disorders and Schizophrenia for School-Aged Children (K-SADS)-The K-SADS is a semistructured interview designed for use with adolescents. ${ }^{18}$ Both self-injury and ED diagnosis were assessed using this interview. Excellent reliability was found across all diagnoses $(k=0.93)$.

Self-Injurious Thoughts and Behaviors Interview (SITBI)—Participants' self-injury history was assessed at baseline using the SITBI. ${ }^{19}$ This instrument has demonstrated strong inter-rater reliability $(k=0.99)$, test-re-test reliability $(k=0.70)$, and predictive validity. ${ }^{19}$

Ecological Momentary Assessment (EMA)_EMA data were captured in real-time using palm pilots. Data collection involved event-contingent responses (i.e., participants were asked to self-initiate answers to questions whenever they experienced self-destructive thoughts/behaviors), which is typically used to gather data focused on a distinct timepoint. ${ }^{10}$ This method optimized our ability to gather relevant information about stressors and contextual variables surrounding specific moments during which the adolescent was experiencing NSSI and/or BP thoughts/behaviors. Questions such as "what were you doing [when you had the thought]?" and "what led to the thought?" were asked each time the participant began an event-contingent recording. Self-destructive thoughts and behaviors assessed included suicide thoughts and behaviors, NSSI thoughts/behaviors, binge/ purge (BP) thoughts/behaviors, and "other" self-destructive thoughts/behaviors (unsafe sex, substance use, impulsive spending, etc.). In the case that more than one thought was reported at a time, the palm pilots captured details on immediate physical, social, and emotional contexts of the most serious thought. Priority was given to suicidal thoughts first, NSSI thoughts next (if no suicidal thoughts), and otherwise the most serious other thought, defined by the adolescent as the thought they most seriously considered acting upon in that moment (see Fig. 1. for details on the hierarchy used). Because of the hierarchical data collection, it is not possible to confirm if all information regarding binge/purge symptoms was collected when binge/purge thoughts co-occurred with NSSI thoughts. However, adequate data were present for preliminary analyses. Participants were asked to report thoughts and behaviors over the span of 14 days. This time frame was chosen in order to capture sufficient data while taking into consideration EMA compliance typically reduces after $1-2$ weeks of data collection. ${ }^{20}$ Actual data collection time varied, averaging 12 days of data (range $=2-26$ days) collected over 23 days of reporting (range $=7-96$ days). 


\section{Data Analysis}

Descriptive analyses were conducted to describe the frequency of BP and co-occurring selfdestructive thoughts. Our primary focus was to compare BP thoughts with NSSI thoughtsoccurring together or in isolation. We excluded thoughts of suicide, which were rare, as well as other self-destructive thoughts, such as unsafe sex, substance abuse, and impulsive spending. We compared the contexts of BP and NSSI thoughts by grouping event log recordings into the following three thought groups, namely, (1) NSSI thought and BP thought (NSSI+BP), (2) NSSI thought without a BP thought (NSSI), and (3) BP thought without a NSSI thought (BP). We also compared the contexts surrounding behaviors in these same three categories. These three categories were compared because participants were recruited specifically for recent NSSI behavior, and we hypothesized that BP thoughts/ behaviors occurring on days with NSSI thoughts/behaviors may have been impacted by different stressors than BP thoughts/behaviors occurring in isolation. These groupings therefore permitted us to analyze the ways that contextual variables may have varied for these two sets of symptoms.

\section{Results}

Table 1 summarizes demographic characteristics of the 30 participating adolescents. The vast majority of the sample was female and Caucasian. Fifty percent of the adolescents had major depressive disorder, and just over $25 \%$ had generalized anxiety disorder. Across all 30 participants, self-destructive thoughts were reported at 481 event-signal recordings over 345 person-days (averaging 11.5 event-days per participant). Self-destructive behaviors were reported at a total of 167 event-signal recordings (35\%). At each event-signal recording, the number of self-destructive thoughts per participant ranged from 1 to $14($ mean $=3)$ and the number of self-destructive behaviors ranged from 0 to $4($ mean $=0.7)$.

\section{Bingeing and Purging Thoughts/Behaviors}

BP thoughts were reported by 22 (73\%) participants at a total of 131 (27\%) recordings. Specifically, 21 participants reported a total of 88 bingeing thoughts (range $=1-23$ thoughts per participant), and 14 participants reported 67 purging thoughts (range 1-15 thoughts per participant) during the 2-week reporting period. Of the 22 participants with a BP thought, 13 (59\%) actually engaged in BP behavior at a total of 60 recordings (46\% of recordings with a BP thought). Specifically, 12 participants reported 53 episodes of bingeing (range $=1-20$ acts per participant) and 6 participants reported 12 episodes of purging (range $=1-5$ acts per participant).

\section{Co-occurring Thoughts}

The majority of recordings (72\%) had at most two thoughts reported. By far the most predominant thought was NSSI, which was reported at almost three-fourths of recordings, and often (at $27 \%$ of recordings) was the only thought. Bingeing thoughts occurred alone at 19 recordings $(4.0 \%)$ but were 3-4 times more likely to occur in combination with other thoughts ( $n=69$ recordings, $14.3 \%$ ). Purging thoughts were 12 times more likely to occur with other thoughts ( $n=62$ recordings; $12.9 \%$ ) than alone ( $n=5$ recordings; $1.0 \%$ ). NSSI thoughts with BP thoughts (NSSI+BP) were reported at 84 recordings (17.5\%) among 16 participants, NSSI thoughts without BP thoughts (NSSI) were reported at 249 recordings (51.8\%) among 28 participants, and BP thoughts without NSSI thoughts (BP) were reported at 42 recordings (8.7\%) among 15 participants. NSSI+BP behaviors were reported during 19 recordings (11.4\%) among 6 participants, NSSI behaviors without BP were recorded during 83 recordings (49.7\%) among 24 participants, and BP behaviors without NSSI were reported at 16 recordings $(9.6 \%)$ among 7 participants. 


\section{Environmental Context of Thoughts}

Social context, activities, and emotions surrounding thoughts were varied across all three thought groups. Participants were more often with friends/peers when NSSI+BP $(40.5 \%)$ or BP only (50.0\%) thoughts were present, compared to when NSSI-only (30.4\%) thoughts were present. Participants were alone much of the time when experiencing BP or NSSI thoughts (32.6\%-41.1\% across all three groups), and only seldom with family members (11.1-15.7\% across groups).

Compared with the NSSI-only thought group, participants were more likely to be already eating when thoughts of BP (with or without NSSI) arose (during 33.3\% of BP thoughts, $25.8 \%$ of NSSI+BP thoughts, and only $6.3 \%$ of NSSI thoughts). Further, criticism/insult was more likely to have triggered thoughts of BP alone (26.2\%) than thoughts of NSSI+BP $(7.9 \%)$ or NSSI alone $(8.2 \%)$. Individuals were also more likely to have felt rejected/hurt at the time of a BP thought (47.6\%) compared to NSSI+BP thoughts (12.4\%) or NSSI thoughts $(21.1 \%)$. They were also more likely to have felt sad/worthless at the time of a BP thought $(52.4 \%)$ compared to an NSSI+BP thought (27.0\%) or NSSI thought (38.2\%). Participants rarely ( $<5 \%$ of recordings) reported peer pressure (i.e., others encouraging self-injurious thoughts/behaviors) to be the source of their self-injurious thoughts.

\section{Motivation for Behaviors}

Whereas the majority of NSSI behaviors (with or without BP) were done to rid the participants of anxiety or bad thoughts (63.2-65.1\%), motivations behind BP-only behaviors were more varied. Approximately one-third (31.3\%) of BP behaviors were engaged in to rid the participant of a thought or feeling (often anxiety, anger, or sadness); one-third (31.3\%) were done to feel something or to escape, and a little over one-third (37.5\%) occurred for other reasons, including lack of control ( $n=3$ recordings), attempts to have fun or feel happy ( $n=2$ recordings), or because of restlessness/worry ( $n=1$ recording).

\section{Discussion}

To our knowledge, this is the first investigation of BP symptoms in adolescents who recently engaged in NSSI using EMA methodology. The adolescents in our sample were generally compliant with recording, providing evidence that EMA methodology is feasible in this population. We found a high rate of BP symptomatology in this sample, which confirms our first hypothesis and is consistent with research noting self-injurious behaviors and eating disorder pathology often co-occur in adolescents. ${ }^{2,21}$ Although participants typically either binged or purged (but not both) over the data collection period, BP thoughts rarely occurred in isolation. Thus, if self-injurious adolescents are experiencing BP thoughts, it is likely they are experiencing other self-destructive thoughts as well. These results highlight that BP symptoms are common among adolescents who engage in NSSI and their self-report may represent an affect regulation strategy or an expression of impulsivity. Finally, because the majority of participant responses focused on thoughts rather than behaviors, the current data may also provide insight into potential contextual settings to counter maladaptive thoughts before they transition to behaviors.

We identified a few striking patterns differentiating the groups with regard to social context, activities, and affect surrounding BP and NSSI thoughts/behaviors. While peer influences have been shown to contribute to the development of eating disorder symptoms ${ }^{22}$ and engagement in NSSI [e.g., contagion or conflict ${ }^{23,24}$ ], we found that the presence of peers preceded BP thoughts more frequently than NSSI thoughts. This is consistent with findings from the original study by Nock et al. ${ }^{17}$, which found that being alone predicted engagement in self-injury. ${ }^{17}$ We speculate that adolescents may be more vul-nerable to experiencing BP 
thoughts when with peers than when alone, given research that has demonstrated individuals with eating disorder symptoms may fear negative evaluation from others, ${ }^{25}$ and that social comparisons can trigger eating disorder-related thoughts. ${ }^{26}$

This association between BP symptoms and being with peers is consistent with the finding that criticism was a more salient trigger for BP thoughts (with or without NSSI thoughts) than for thoughts about NSSI only. Bearing in mind that the adolescents were most frequently with friends or peers when endorsing BP thoughts, it is possible that during social engagement they experienced more direct criticism regarding their body/shape from their friends/peers. Peer criticism and teasing can lead to greater body dissatisfaction, a documented risk factor for the development of eating disorders. ${ }^{27,28}$ Future EMA research that examines the focus of criticism (i.e., asks additional questions to ascertain whether criticism is about body/shape, academics, friends, or other), as well as how and whether different types of criticism predict the presence of BP thoughts would be informative.

Consistent with previous EMA research, ${ }^{6,8}$ negative emotions were present both before and while having BP and NSSI thoughts. Participants reported a range of emotions, with sadness/worthlessness and rejection/hurt being the most frequent feelings reported before BP thoughts occurred. Given that specific emotions (e.g., feeling rejected) were found to predict self-injury in earlier work, ${ }^{17}$ future research might investigate if the specific form of negative affect (e.g., sadness, self-hatred) is more influential in triggering BP behaviors than simply the presence of generally negative emotions. Such data may have treatment implications and might be used in cognitive behavior therapy to identify specific affect/ behavior associations. That is, a clinician could help a patient to identify specific emotions that typically precede maladaptive thoughts; further research is necessary to illuminate whether intervening on these maladaptive thoughts (e.g., by engaging in a more constructive coping response) may help reduce the likelihood that the adolescent engages in the behavior.

Those who actually engaged in NSSI (i.e., participants in the NSSI and NSSI+BP behavior groups) most frequently cited a desire to rid themselves of a thought/feeling as the reason for their behavior, which aligns with the theory that self-injurious behavior is a maladaptive mechanism for reducing negative feelings. ${ }^{29}$ In comparison, the reasons for BP behaviors were more ambiguous. These adolescents may be turning to self-injury more frequently to regulate negative emotions, and may be engaging in BP behaviors because of other types of stress or feelings (e.g., lack of control) not captured in the EMA options. Across behavior groups, these data must be interpreted with caution because the participants may not have had insight into the specific antecedents that preceded their behavior. Rather, these descriptions may simply reflect their accounts or explanations.

Strengths of this study include the use of novel real-time data collection in an adolescent sample and the detailed investigation of BP symptoms, their co-occurrence with other selfdestructive thoughts and behaviors, and their contexts. Nonetheless, important limitations existed. The focus and hierarchy of the questions asked via EMA revolved around thoughts of suicide and NSSI rather than BP. Therefore, when BP thoughts co-occurred with suicidal or NSSI thoughts, follow-up questions were asked about the suicidal/NSSI thoughts, and not the BP thoughts. To better contextualize BP thoughts, we grouped BP thoughts based on whether or not they co-occurred with NSSI thoughts, which resulted in smaller group sizes that limited us to descriptive analyses only. Additionally, our sample was comprised of primarily Caucasian females, which may limit external validity, though the literature suggests that like EDs, NSSI symptoms are more common among adolescent females than males. ${ }^{30}$ Finally, as with all EMA studies, there were missing data and all data were subject to self-report biases and limitations. ${ }^{31,32}$ Specifically, we cannot confirm that all thoughts/ behaviors that occurred were recorded. 
Despite these limitations, the current analysis offers important information regarding binge/ purge symptoms in high-risk adolescents and provides a foundation for further research. Our preliminary findings show that BP thoughts are common and may be a strong indicator that a NSSI adolescent is experiencing concurrent self-destructive thoughts. While we identified a number of unique predictors of BP thoughts, predictors of self-destructive thoughts were less clear, and varied more with respect to context. Nonetheless, the results of these descriptive analyses may inform interventions by identifying specific contextual variables that could be targeted during treatment. Future EMA studies in adolescents diagnosed with full threshold eating disorders, as well as samples with and without self-injury, might examine the broad range of eating disorder symptoms (e.g., restricting, excessive exercising) and delineate contextual variables that might increase risk for eating disorder thoughts and identify factors that predict the progression of thoughts into behaviors.

\section{Acknowledgments}

This research was supported by the American Foundation for Suicide Prevention (MKN). Manuscript preparation was supported by the Matina Horner Fellowship, Harris Center for Education and Advocacy in Eating Disorders at Massachusetts General Hospital (RMS, JY), and F31MH097308 (RMS). The content is solely the responsibility of the authors and does not necessarily represent the official views of the National Institutes of Health.

\section{References}

1. Svirko E, Hawton K. Self-injurious behavior and eating disorders: The extent and nature of the association. Suicide Life Threat Behav. 2007; 37:409-421. [PubMed: 17896881]

2. Ross S, Heath NL, Toste JR. Non-suicidal self-injury and eating pathology in high school students. Am J Orthopsychiatry. 2009; 79:83-92. [PubMed: 19290728]

3. Haedt-Matt AA, Keel PK. Revisiting the affect regulation model of binge eating: A meta-analysis of studies using ecological momentary assessment. Psychol Bull. 2011; 137:660-681. [PubMed: 21574678]

4. Smyth J, Wonderlich S, Crosby R, Miltenberger R, Mitchell J, Rorty M. The use of ecological momentary assessment approaches in eating disorder research. Int J Eat Disord. 2001; 30:83-95. [PubMed: 11439412]

5. Anestis MD, Silva C, Lavender JM, Crosby RD, Wonderlich SA, Engel SG, et al. Predicting nonsuicidal self-injury episodes over a discrete period of time in a sample of women diagnosed with bulimia nervosa: An analysis of self-reported trait and ecological momentary assessment based affective lability and previous suicide attempts. Int J Eat Disord. 2012; 45:808-811. [PubMed: 21744378]

6. Armey MF, Crowther JH, Miller IW. Changes in ecological momentary assessment reported affect associated with episodes of nonsuicidal self-injury. Behav Ther. 2011; 42:579-588. [PubMed: 22035987]

7. Wegner KE, Smyth JM, Crosby RD, Wittrock D, Wonderlich SA, Mitchell JE. An evaluation of the relationship between mood and binge eating in the natural environment using ecological momentary assessment. Int J Eat Disord. 2002; 32:352-361. [PubMed: 12210650]

8. Crosby RD, Wonderlich SA, Engel SG, Simonich H, Smyth J, Mitchell JE. Daily mood patterns and bulimic behaviors in the natural environment. Behav Res Ther. 2009; 47:181-188. [PubMed: 19152874]

9. Smyth JM, Wonderlich SA, Sliwinski MJ, Crosby RD, Engel SG, Mitchell JE, et al. Ecological momentary assessment of affect, stress, and binge-purge behaviors: Day of week and time of day effects in the natural environment. Int J Eat Disord. 2009; 42:429-436. [PubMed: 19115371]

10. Shiffman S, Stone AA, Hufford MR. Ecological momentary assessment. Annu Rev Clin Psychol. 2008; 4:1-32. [PubMed: 18509902]

11. Fairburn CG, Harrison PJ. Eating disorders. Lancet. 2003; 361:407-416. [PubMed: 12573387] 
12. Muehlenkamp JJ, Claes L, Havertape L, Plener PL. International prevalence of adolescent nonsuicidal self-injury and deliberate self-harm. Child Adolesc Psychiatry Ment Health. 2012; 30:10 18. [PubMed: 22462815]

13. Forbes EE, Stepp SD, Dahl RE, Ryan ND, Whalen D, Axelson DA, et al. Real-world affect and social context as predictors of treatment response in child and adolescent depression and anxiety: An ecological momentary assessment study. J Child Adolesc Psychopharmacol. 2012; 22:37-47. [PubMed: 22339611]

14. Van Zundert RM, Boogerd EA, Vermulst AA, Engels RC. Nicotine withdrawal symptoms following a quit attempt: An ecological momentary assessment study among adolescents. Nicotine Tob Res. 2009; 11:722-729. [PubMed: 19423695]

15. Hilbert A, Rief W, Tuschen-Caffier B, de Zwaan M, Czaja J. Loss of control eating and psychological maintenance in children: An ecological momentary assessment study. Behav Res Ther. 2009; 47:26-33. [PubMed: 19010458]

16. Muehlenkamp JJ, Engel SG, Wadeson A, Crosby RD, Wonderlich SA, Simonich H, et al. Emotional states preceding and following acts of non-suicidal self-injury in bulimia nervosa patients. Behav Res Ther. 2009; 47:83-87. [PubMed: 19027892]

17. Nock MK, Prinstein MJ, Sterba SK. Revealing the form and function of self-injurious thoughts and behaviors: A real-time ecological assessment study among adolescents and young adults. J Abnorm Psychol. 2009; 118:816-827. [PubMed: 19899851]

18. Kaufman J, Birmaher B, Brent D, Rao U, Flynn C, Moreci P, et al. Schedule for affective disorders and schizophrenia for school-age children-present and lifetime version (K-SADS-PL): Initial reliability and validity data. J Am Acad Child Adolesc Psychiatry. 1997; 36:980-988. [PubMed: 9204677]

19. Nock MK, Holmberg EB, Photos VI, Michel BD. Self-injurious thoughts and behaviors interview: Development, reliability, and validity in an adolescent sample. Psychol Assess. 2007; 19:309-317. [PubMed: 17845122]

20. Broderick JE, Schwartz JE, Shiffman S, Hufford MR, Stone AA. Signaling does not adequately improve diary compliance. Ann Behav Med. 2003; 26:139-148. [PubMed: 14534031]

21. Peebles R, Wilson JL, Lock JD. Self-injury in adolescents with eating disorders: Correlates and provider bias. J Adolesc Health. 2011; 48:310-313. [PubMed: 21338905]

22. Shroff H, Thompson JK. Peer influences, body-image dissatisfaction, eating dysfunction and selfesteem in adolescent girls. J Health Psychol. 2006; 11:533-551. [PubMed: 16769734]

23. Deliberto TL, Nock MK. An exploratory study of correlates, onset, and offset of non-suicidal selfinjury. Arch Suicide Res. 2008; 12(3):219-231. [PubMed: 18576203]

24. Yip B. A multi-dimensional perspective of adolescents' self-cutting. Child and Adolescent Mental Health. 2005; 10:80-86.

25. Gilbert N, Meyer C. Fear of negative evaluation and the development of eating psychopathology: A longitudinal study among nonclinical women. Int J Eat Disord. 2005; 37:307-312. [PubMed: 15856504]

26. Leahey TM, Crowther JH, Ciesla JA. An ecological momentary assessment of the effects of weight and shape social comparisons on women with eating pathology, high body dissatisfaction, and low body dissatisfaction. Behav Ther. 2011; 42:197-210. [PubMed: 21496506]

27. Jones DC, Vigfusdottir TH, Lee Y. Body image and the appearance culture among adolescent girls and body: An examination of friend conversations, peer criticism, appearance magazines, and the internalization of appearance ideals. J Adolesc Res. 2004; 19:323-339.

28. Stice E, Shaw HE. Role of body dissatisfaction in the onset and maintenance of eating pathology: A synthesis of research findings. J Psychosom Res. 2002; 53:985-993. [PubMed: 12445588]

29. Nock MK, Prinstein MJ. A functional approach to the assessment of self-mutilative behavior. J Consult Clin Psychol. 2004; 72:885-890. [PubMed: 15482046]

30. Laye-Gindhu A, Schonert-Reichl KA. Nonsuicidal self-harm among community adolescents: Understanding the"whats" and "whys" of self-harm. J Youth Adolesc. 2005; 34:447-457.

31. Nisbett RE, Wilson TD. Telling more than we can know: Verbal reports on mental processes. Psychol Rev. 1977; 84:231-259. 
32. Takarangi MK, Garry M, Loftus EF. Dear diary, is plastic better than paper? I can't remember: Comment on Green, Rafaeli, Bolger, Shrout, and Reis. Psychol Methods. 2006; 11:119-122. discussion 123-125. [PubMed: 16594772] 


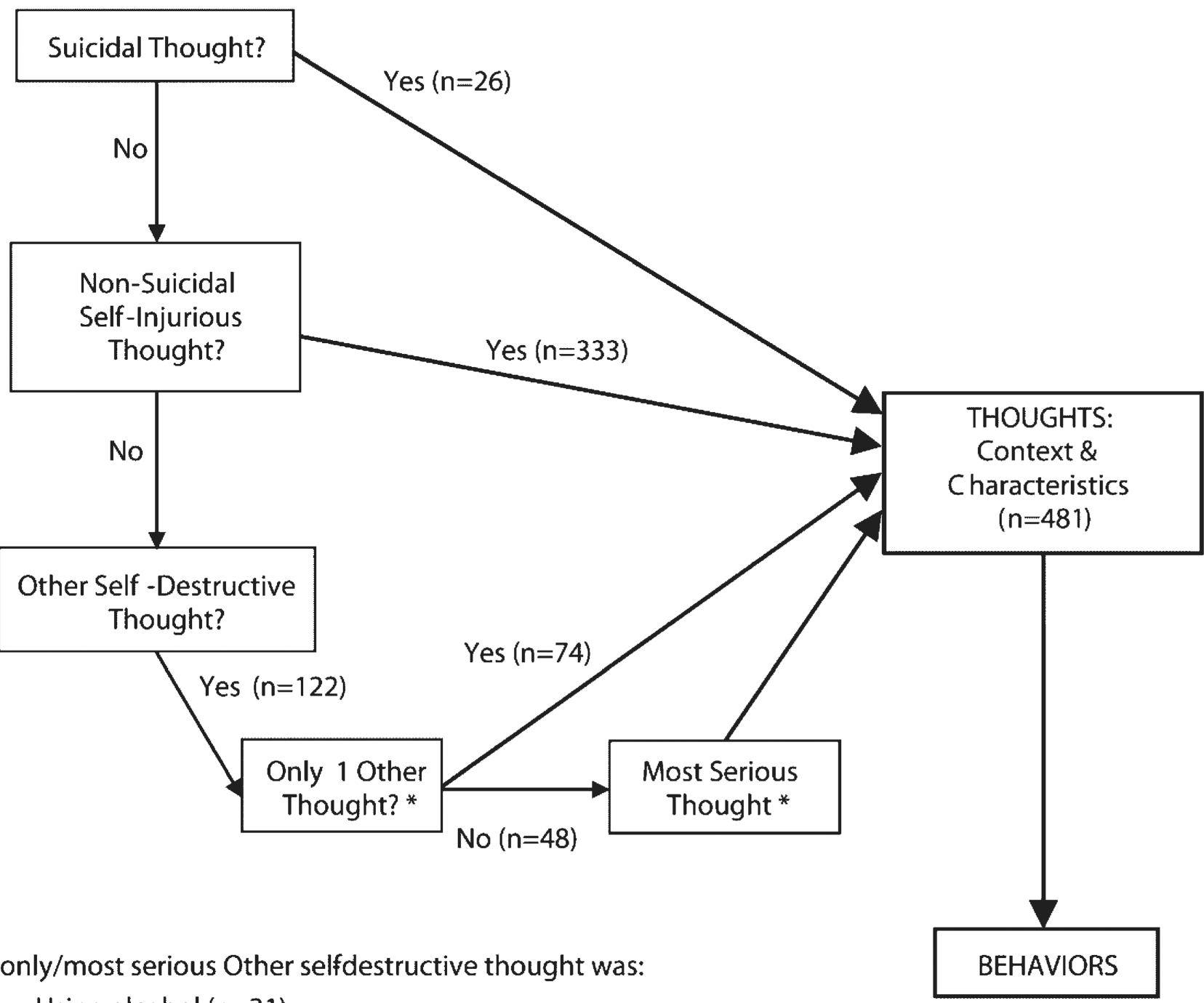

* The only/most serious Other selfdestructive thought was:

Using alcohol $(n=31)$

Using drugs/pills $(n=36)$

Spending impulsively $(n=11)$

Binge eating $(n=25)$

Purging $(n=8)$

Unsafe sex $(n=2)$

Other risky behavior $(n=9)$

Figure 1.

Hierarchy for thought context data (if $>1$ thought present per session). Participants were asked to create an event log entry for every self-destructive thought they had, and scheduled reminders were programmed each day. If participants reported thoughts about suicide, NSSI, and other self-destructive thoughts at a given session in the event log, the hierarchy shown here was used to determine which thought would be the focus of subsequent contextual questions asked. Numbers in parentheses reflect the number of sessions recorded. In addition to the 481 event log sessions represented, participants recorded 436 bedtime log sessions with information about general health, mood, and stress felt that day. 


\section{TABLE 1}

Demographic characteristics of 30 EMA participants.

\begin{tabular}{|c|c|c|c|}
\hline & Mean & (SD) & Range \\
\hline Age (Yr) & 17 & 1.9 & $12-19$ \\
\hline $\operatorname{BMI}(n=21)$ & 23 & 3.7 & $17.7-32.9$ \\
\hline BMI percentile & 58 & 27.5 & $0.7-99.5$ \\
\hline \multirow[t]{2}{*}{ BMI $z$-score } & 0.5 & 1.0 & $-0.9-2.8$ \\
\hline & Number of Participants & $(\%)$ & \\
\hline \multicolumn{4}{|l|}{ Gender } \\
\hline Female & 26 & 87 & \\
\hline Male & 4 & 13 & \\
\hline Race & 26 & 87 & \\
\hline Caucasian/white & 4 & 13 & \\
\hline Hispanic & 2 & 7 & \\
\hline Asian & 1 & 3 & \\
\hline Other & 1 & 3 & \\
\hline \multicolumn{4}{|l|}{ Current disorders ${ }^{*}$} \\
\hline MDD & 15 & 50 & \\
\hline Mania & 1 & 3 & \\
\hline Panic & 3 & 10 & \\
\hline Social phobia & 4 & 13 & \\
\hline Specific phobia & 4 & 13 & \\
\hline GAD & 8 & 27 & \\
\hline OCD & 2 & 7 & \\
\hline Anorexia nervosa & 1 & 3 & \\
\hline Bulimia nervosa & 3 & 10 & \\
\hline ODD & 2 & 7 & \\
\hline Conduct disorder & 2 & 7 & \\
\hline Alcohol abuse & 7 & 23 & \\
\hline Substance abuse & 4 & 13 & \\
\hline PTSD & 6 & 20 & \\
\hline
\end{tabular}

$\mathrm{GAD}=$ generalized anxiety disorder; $\mathrm{MDD}=$ major depressive disorder; $\mathrm{OCD}=$ obsessive-compulsive disorder; $\mathrm{ODD}=$ oppositional defiant disorder; PTSD = post-traumatic stress disorder. 